\title{
La desafortunada elección del Procurador
}

El Estado de Derecho es esc orden social ideal en el que todos y cada uno de los actores sociales están dispuestos a regir su comportamiento de acuerdo con una serie de normativas, cuyo fin es garantizar el funcionamiento armónico de la sociedad. Lo que ha de predominar, pues, en una sociedad que persiga tal ideal, es el respeto irrestricto a las leyes. Si un orden social ha de estar regido por normas, la regla básica tácita y fundamental es que todos los que lo integran se comprometan a adecuar su conducta a las normativas que en él se establezcan. De lo contrario, cualquier esfuerzo por consolidar un Estado de Derecho fracasaría inexorablemente.

En un escenario democrático, los encargados de establecer las normas son los legisladores. Los ciudadanos han puesto en ellos la responsabilidad de representar sus intereses en el pleno a la hora de determinar qué leyes son convenientes y afines a sus necesidades. Es por eso que cuando los mismos legisladores se niegan a proceder de forma legal, tanto el sistema democrático como el Estado de Derecho empiezan a flaquear peligrosamente.

Pues bien, eso fue justamente lo que sucedió con la elección del procurador para la defensa de los derechos humanos. Ante todo, esta tardanza resulta del todo injustificable. Es incomprensible que los nombres de los posibles sustitutos de Victoria Marina Vázquez de Avilés sólo empezaran a barajarse cuando ésta, prácticamente, ya había finalizado su mandato. El sentido común más primario indica que los encargados de elegir a la per- sona que relevará a otra de un cargo deben empezar a considerar las alternativas con antelación, por un espacio de tiempo mínimamente razonable. Pero eso no se dio en este caso. Resulta que los diputados no sólo iniciaron tarde e improvisadamente el proceso de elección del nuevo procurador, sino que, además, lo retrasaron hasta el punto de convertirlo en un proceso confuso y sospechoso.

Más de cuatro meses hubo que esperar para que en la Asamblea Legislativa se comenzara a ver más o menos claro a quien se nombraría como responsable de la Procuraduría para la Defensa de los Derechos Humanos (PDDH). Un desfile interminable de nombres y una sucesión improductiva de reuniones fueron notas características de ese período. Era evidente que la tardanza tenía que ver con fuertes dosis de negligencia y despreocupación por parte de las diversas fracciones legislativas. Pero pronto se hizo evidente que el entrampamiento en la elección del sucesor de Vázquez de Avilés obedecía a intereses políticos del todo ajenos a la institución en cuestión. Y éste último fue, sin lugar a dudas, el obstáculo más grave. Una cosa era que los diputados erraran por incompetencia o por ignorancia y otra muy distinta que sus aparentes desaciertos fueran decisiones concebidas en función de la conveniencia de sus respectivos partidos y no de la de la nación.

Tempranamente se supo que los problemas en la elección del procurador tenían que ver con que el Partido Demócrata Cristiano había negociado de antemano con ARENA la silla de la Procuraduría, a cambio de votos a favor para aprobar el Presu- 
puesto General de la Nación. Un tiempo después apareció de repente -impulsado por Ronal Umaña, Secretario General de la Democracia Cristiana- la figura de Eduardo Peñale Polanco como posible reemplazo de la ex procuradora. Luego se extendió pronto el rumor de que, para conquistar el respaldo del FMLN, el jurista prometió mantener en sus cargos a los simpatizantes del partido de izquierda que laboraran en la institución. Y, al parecer, así fue como, después de meses de deliberación, 77 diputados pusieron en manos de Peñate Polanco la PDDH.

Las protestas de múltiples organismos no gubernamentales no se hicieron esperar. $\mathrm{Y}$ no era para menos. Que tan prolongada tardanza culminara en la elección de la persona menos apta para el cargo era - y sigue siendo-, desde todo punto de vista, injustificable. Como es bien sabido ya, el actual procurador tenía abiertos más de 20 expedientes al momento de ser elegido. En la Corte Suprema de Justicia, en el Consejo Nacional de la Judicatura y en la misma PDDH, recaía sobre él un rosario de denuncias que iban desde retardación de justicia hasta acoso sexual, pasando por violación al derecho de audiencia y de defensa, entre otros. Al final, resultó que tantos meses y discusiones Iranscurrieron en vano: la Asamblea Legislativa terminó poniendo al mando de la Procuraduría a un jurista que aún enlrenta acusaciones de variada índole, inclusive por violación a los derechos humanos.

El mes que siguió a dicha elección estuvo marcado por la polémica en torno a la moralidad y aptitud de Peñate. La opinión pública se dedicó a cuestionar la decisión de los diputados mientras que estos intentaban defenderse, arguyendo la espera de los resultados de una investigación que, sólo hasta entonces, emprendieron en torno a la trayectoria del funcionario. Otro hecho incomprensible. ¿No hubiera sido acaso mucho más razonable investigar a Polanco -0 a cualquier otro que hubicra sido el aspirante - antes de elegirlo?

Los avances de la investigación pusieron de manificsto que el historial del procurador electo no podía ser más dudoso. El FMLN y la Unión Social Cristiana (USC) terminaron por retractarse y reconocieron su error. Pero los demás partidos se aferraron cada vez más a la insostenible idea de que Peñate Polanco era "la persona idónea" para dirigir la PDDH. A esas alturas, la ratificación no exigía más que la mayoría simple. Así, los institutos políticos pudieron llevarla a cabo, prescindiendo tanto del Frente como de la Unión Social Cristiana.

Y éste es, a grandes rasgos, el recuento de los hechos que llevaron a Eduardo Peñate Polanco a la cabeza de la PDDH. Es evidente que todo el proceso estuvo regido por componendas y acuerdos que nada tenían que ver con la importancia de la Procuraduría. Si ha habido durante la gestión del actual Órgano Legislativo una demostración indiscutible de la poca o nula disposición de los diputados a actuar conforme a los dictámenes legales, esa ha sido la elección del nuevo procurador. Los mismos funcionarios que en innumerables ocasiones se han comprometido a fortalecer el Estado de Derecho y a luchar por la consolidación de la democracia, esta vez demosiraron que tal compromiso no es más que retórica y demagogia.

Ahora bien, hay que decir que en nada sorprende que ARENA haya comprometido el cargo del procurador con el fin de obtener respaldo a una iniciativa de su conveniencia. En primer lugar, distintos hechos han demostrado que el partido en el gobierno no sólo no está dispuesto a llegar hasta las últimas consecuencias cuando de velar por los derechos de la ciudadanía se trata, sino que, además, en varias ocasiones ha defendido a ultranza proyectos que van en desmedro de los mismos la reacción lirente a los problemas laborales de las maquilas, la Ley de Emergencia contra la Delincuencia y la manera en la que se hizo frente a la problemática del gremio médico, son sólo algunos ejemplos de ello.

En segundo lugar, se sabe bien que el partido oficial carece de escrúpulos cuando de poner en manos de sus aliados políticos determinadas instituciones se trata. De ese modo garantiza el apoyo incondicional de estos a la hora de requerir los beneficios de sus favores. Tal es el caso de la Corte de Cuentas, dominio del PCN; y ahora de la PDDH, territorio de la Democracia Cristiana. Así, las instituciones a las que corresponde por naturaleza supervisar la gestión del Estado y evitar los abusos de poder quedan atadas de manos.

La elección de Peñate Polanco resulta del todo conveniente al partido en el gobierno, pues no hay que olvidar que, durante los tres años que duró su gestión, el desempeño de la ex procuradora fue 
para el gobierno arenero más un estorbo que una bandera que izar a la hora de vanagloriarse de su administración, especialmente en el área de la seguridad pública. Ahora, con un procurador pedecista al mando, difícilmente habrá confrontaciones; de seguro el instituto político gobernante no tendrá quejas.

No era, entonces, ni de ARENA ni de ningún otro partido de derecha de quien hubiera podido esperarse que emergiera una elección mínimamente satisfactoria. De quien sí cabía esperar una posición firme y comprometida en el momento de decidir quićn sucedería a Vázquez de Avilés en la Procuraduría era de los institutos políticos de centro y de izquierda. Y no es que se piense que velar por el cumplimiento de los derechos humanos no lorma parte de los roles del Estado. Claro que los derechos de la ciudadanía competen al Estado.

Idcalmente, la PDDH debería ser la entidad más importante en matcria de derechos humanos y las distintas instancias gubernamentales deberían estar dispuestas a facilitar su trabajo. Los acuerdos de paz, la suscripción a distintos tratados internacionales y gran parte de los discursos presidenciales demuestran que los dos últimos mandatarios salvadoreños se han comprometido, en teoría, a defender decididamente los derechos fundamentales. Pero, como se señaló anteriormente, fuertes intereses políticos impiden, tanto al partido gobernante como a sus allegados, procurar la puesta en práctica de tales tratados y compromisos.

Pero los partidos de oposición forman también parte del Estado y se ha visto que, en ciertas coyunturas - la derogación de la Ley de Privatización de ANTEL, por ejemplo-, su participación puede llegar a ser determinante. Es por eso que el accionar del FMLN en esta coyuntura resulta hasta la fecha incomprensible. No hay que olvidar que la PDDH se creó obedeciendo a uná exigencia suya, plasmada en las negociaciones que pusieron fin a la guerra. Dilícilmente esta entidad existiría hoy en día por iniciativa del poder político tradicional.

La defensa de los derechos humanos es competencia del Estado; del Estado en su conjunto y no sólo de una de sus entidades. Pero falta mucho aún para que todos los que lo conforman asuman la responsabilidad de garantizar su cumplimiento. Por esa razón, el compromiso con los derechos fundamentales de la población recaía en quienes mayores muestras habían dado de estar interesados en hacerlos valer. Lograr la creación de la PDDH imponía a la izquierda, hoy democrática, la obligación moral y política de procurarle el mejor de los directores posible.

El hecho de que el FMLN y la Convergencia Democrática hallan avalado la elección de Peñate es del todo inconsecuente con el supuesto interés de hacer cumplir los derechos humanos que la izquierda puso de manifiesto al haber planteado la creación de dicha institución como una de las condiciones para la firma de la paz. En especial, si tomamos en cuenta que algunas de las denuncias contra ese funcionario ya eran conocidas por los diputados en el momento de imprimir las firmas que daban la anuencia a su posicionamiento. ¿Habrá que pensar que el interés inicial de la izquierda salvadoreña por los derechos fundamentales de la ciudadanía no era genuino? ¿O es que acaso la vida democrática ha trastocado por completo la jerarquía de sus "causas"?

Hasta antes de toda esta larga controversia no parecía un disparate asegurar que, si bien era cier-

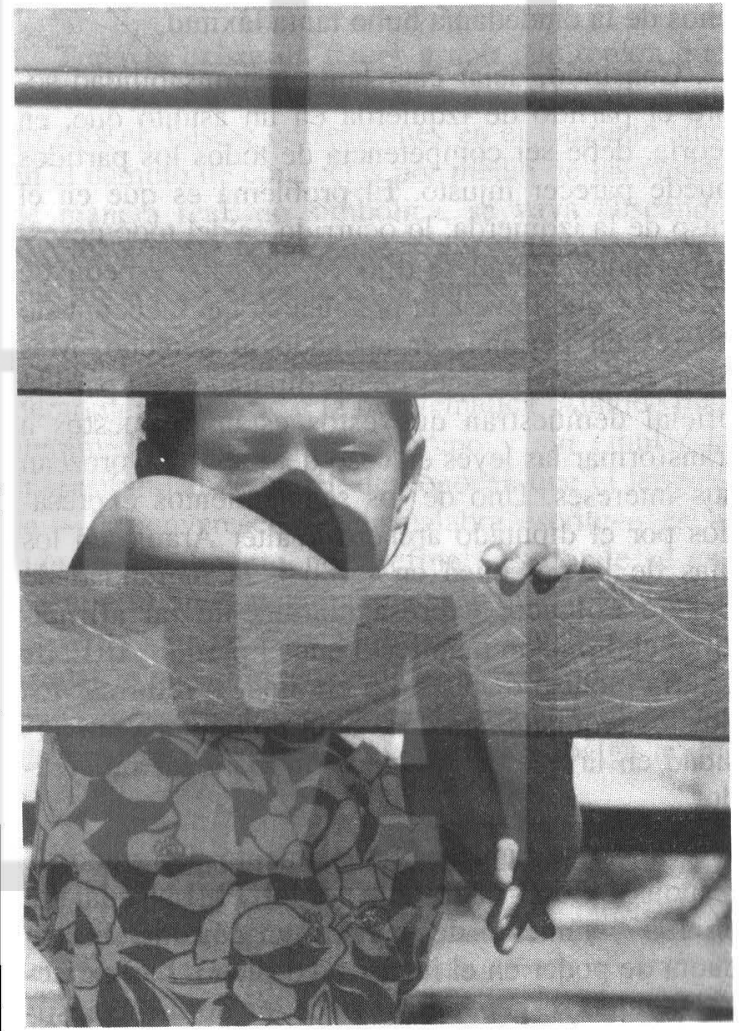


to que al FMLN podían achacársele ciertos males lamentables, entre ellos no podían incluirse los tradicionales vicios de la política: compadrazgos, componendas, tráfico de influencias. Ahora, después de haber contribuido a la elección de un procurador para la defensa de los derechos humanos que no cumple con los mínimos requisitos ni morales ni profesionales para ocupar tal cargo, la rectitud de dicho partido, al menos en el aspecto señalado, puede ponerse en duda. Cuesta creer que los diputados del Frente canjearan sus votos por un par de plazas. Pero, ¿de qué otro modo se explica que el instituto político de izquierda haya cometido un error tan fácil de predecir, rectificable sólo cuando ya no había nada que se pudiera hacer para enmendarlo?

El FMLN pasó meses haciendo uso de su poder para evitar un sinnúmero de nombramientos, ¿por qué entonces otorgar su voto al más cuestionado de los aspirantes? No se entiende cómo es que su posición, a la hora de defender su rechazo a la política de endeudamiento externo, fue tan firme, mientras que en la elección de la persona encargada de velar por el cumplimiento de los derechos de la ciudadanía hubo tanta laxitud.

Con todo, dejar caer tanta responsabilidad sobre el partido de izquierda en un asunto que, en teoría, debe ser competencia de todos los partidos puede parecer injusto. El problema es que en el caso de la izquierda, lo ocurrido es del todo desesperanzador. Como se dijo ya, no cabe esperar de ARENA que lleve a la práctica su tan mencionado interés en permanecer apegado al derecho. Más bien, las declaraciones de los diputados del partido oficial demuestran que estos están dispuestos a transformar las leyes en caso de que no favorezcan sus intereses. Uno de los señalamientos expresados por el diputado arenero Walter Araujo en los días de la polémica en torno a la moralidad de Peñate Polanco, expresa claramente tal afirmación; el diputado manifestó que el partido ARENA estaría incluso dispuesto a eliminar o reformar todos los requisitos porque "aquí no hay una universidad en la que se gradúe nadie para ser procurador".

Mucho se habló en su momento del grado de responsabilidad adquirida por el FMLN cuando, en 1997, aumentó de manera tan considerable su cuota de poder en el interior del pleno. Las expectativas que se generaron alrededor de dicho insti- tuto político le imponían la obligación de convertirse en una posibilidad real de cambio, en una verdadera alternativa frente al partido oficial y los suyos. Pues bien, su cuestionable accionar en este caso ha defraudado la confianza que los votantes en 1997 le otorgaron.

Ahora no queda más que pensar que ninguno de los partidos está realmente dispuesto a apegarse a las leyes el cien por ciento de las veces, cuando las distintas decisiones por tomar así lo exigen. Que no tenemos el procurador idóneo es un hecho; pero un hecho que sólo puede explicarse porque la Asamblea Legislativa con la que contamos tampoco es la idónea. Por un lado, los diputados areneros pusieron nuevamente de manifiesto lo fácil que es para ellos irrespetar las leyes; pero, por el otro, el FMLN intentó restar importancia a las normas establecidas en la Carta Magna. Ileana Rogel, por ejemplo, intentó aminorar las acusaciones que por retardación de justicia recaían sobre Peñate Polanco, argumentando que la mayor parte de los jueces enfrentaba similares denuncias. Y, siguiendo esa misma lógica, de la controversia surgieron, por parte de los diputados, declaraciones que rayaron en lo absurdo: que se esperaba que el electo procurador corrigiera sus malas prácticas mientras se desempeñaba en la PDDH fue, quizá, la más memorable de ellas.

Así las cosas, el panorama parece bastante oscuro. El partido oficial se llena la boca hablando de su apego a la Constitución, pero no tiene inconveniente alguno en violarla cada vez que sus intereses políticos se lo exigen. De sus aliados políticos, ni qué decir, están resueltos a permanecer incondicionales a ARENA mientras éste les procure ciertas cuotas significativas de poder. Los partidos de oposición sólo ejercen su papel en virtud de contadas iniciativas gubernamentales, respondiendo a razones, por lo demás, bastante confusas.

En definitiva, hablar de que en El Salvador el Estado de Derecho es un hecho, o al menos un proyecto rectamente encaminado, es imposible. En un país en el que los legisladores pasan por alto las leyes y en el que la independencia de las instituciones no puede garantizarse, hacer mención del Estado de Derecho o hablar de una instauración democrática consolidada no evoca nada más que una utopía muy lejana aún.

Carmen Elena Villacorta Zuluaga 